\title{
Genetic risk factors and Covid-19 severity in Brazil: results from BRACOVID
}

4 Alexandre C. Pereira ${ }^{1,2^{*}}$, Taniela Marli Bes ${ }^{2,3}$, Mariliza Velho ${ }^{1}$, Emanuelle Marques ${ }^{1}$, 5 Cintia E Jannes ${ }^{1}$, Karina Ramos Valino ${ }^{1}$, Carla L Dinardo ${ }^{4}$, Silvia Figueiredo Costa ${ }^{3}$, 6 Alberto José da Silva Duarte ${ }^{5}$, Alexandre Ricardo dos Santos ${ }^{6}$, Miguel Mitne-Neto ${ }^{6}$, Jose $7 \quad$ Medina-Pestana ${ }^{7}$, Jose E Krieger ${ }^{1 *}$

$10{ }^{1}$ Laboratorio de Genetica e Cardiologia Molecular, Instituto do Coracao (InCor), 11 Faculdade de Medicina da Universidade de São Paulo, São Paulo, Brazil

$12{ }^{2}$ Genetics Department, Harvard Medical School, MA, USA

$13{ }^{3}$ Divisao de Doenças Infecciosas, Hospital das Clínicas da Universidade de São Paulo,

14 São Paulo, Brazil.

$15{ }^{4}$ Immunohematology, Fundação Pró-Sangue Hemocentro de São Paulo, São Paulo, 16 Brazil.

$17{ }^{5}$ Departamento de Dermatologia, Laboratório de Dermatologia e Imunodeficiências, 18 Faculdade de Medicina e Instituto de Medicina Tropical de São Paulo, Sao Paulo, Brazil.

$19{ }^{6}$ Grupo Fleury, Sao Paulo, Brazil

$20 \quad{ }^{7}$ Hospital do Rim, UNIFESP, Sao Paulo, Brazil

$23 *$ Corresponding author.

24 E-mail: alexandre.pereira@incor.usp.br (ACP), j.krieger@hc.fm.usp.br (JEK) 


\section{Abstract:}

31 The Covid-19 pandemic has changed the paradigms for disease surveillance and rapid

32 deployment of scientific-based evidence for understanding disease biology, susceptibility,

33 and treatment. We have organized a large-scale genome-wide association study in Sars-

34 Cov-2 infected individuals in Sao Paulo, Brazil, one of the most affected areas of the

35 pandemic in the country, itself one of the most affected in the world. Here we present the

36 results of the initial analysis in the first 5,233 participants of the BRACOVID study.

37 We have conducted a GWAS for Covid-19 hospitalization enrolling 3533 cases

38 (hospitalized Covid-19 participants) and 1700 controls (non-hospitalized Covid-19

39 participants). Models were adjusted by age, sex and the 4 first principal components. A

40 meta-analysis was also conducted merging BRACOVID hospitalization data with the

41 Human Genetic Initiative (HGI) Consortia results.

42 BRACOVID results validated most loci previously identified in the HGI meta-analysis.

43 In addition, no significant heterogeneity according to ancestral group within the Brazilian

44 population was observed for the two most important Covid-19 severity associated loci:

453 p21.31 and Chr21 near IFNAR2. Using only data provided by BRACOVID a new

46 genome-wide significant locus was identified on Chr1 near the genes DSTYK and

47 RBBP5. The associated haplotype has also been previously associated with a number of

48 blood cell related traits and might play a role in modulating the immune response in

49 Covid-19 cases. 
medRxiv preprint doi: https://doi.org/10.1101/2021.10.06.21264631; this version posted October 7, 2021. The copyright holder for this preprint

\section{Introduction}

The severe acute respiratory syndrome coronavirus 2 (SARS-CoV-2) was first 57 described in Wuhan, China, in December 2019, and quickly spread across the globe

58 causing a pandemic (1). After 20 months of the beginning of the spread, there were more

59 than 213 million confirmed cases worldwide, with total deaths exceeding 4 million, half

60 million in Brazil alone (2).

61 Clinical outcomes of SARS-CoV-2 infection range from asymptomatic infection 62 to fatal coronavirus disease 2019 (Covid-19). The high mortality rates are predominantly 63 among specific subgroups with predeterminate conditions, such as male sex, older age or 64 having pre-existent cardiovascular, pulmonary, or immune disease. However, many 65 severe clinical cases are not due to comorbidity or constitutional factors. Notably, even 66 among those without pre-existing conditions, inter-individual heterogeneity is striking.

67 The considerable variation in disease behavior among infected individuals highlights the 68 importance of the hosts' genetic background modulating disease presentation (3-5).

Until now a small number of large-scale genome-wide association studies

70 (GWAS) has been conducted with some reproducible identified genetic loci associated 71 with disease susceptibility or severity. A GWAS among 1980 patients from the European 72 Covid-19 epicenters in Italy and Spain, as well as from the less-burdened countries of 73 Germany and Norway was the first study to describe the susceptibility locus at the 74 chromosome 3p21.31 gene cluster and suggested the involvement of the ABO blood75 group system in Covid-19 (6). The GenOMICC study, in addition to replicating the 76 association at chromosome 3 p21.31 as mediator of critical illness, identified associations 77 with disease severity and other genetic variants (7). Finally, early in 2021, the Covid-19 78 Host Genetics Initiative (HGI) has brought together 49.562 cases and 2 million controls,

79 from populations with different ancestries across the world to elucidate the genetic 80 determinants of SARS-CoV-2 infection and severity including 853 samples from the 81 BRACOVID study. From these analyses 15 genome-wide significant loci associated with 82 SARS-CoV-2 infection or Covid-19 were observed (8). 
medRxiv preprint doi: https://doi.org/10.1101/2021.10.06.21264631; this version posted October 7, 2021. The copyright holder for this preprint (which was not certified by peer review) is the author/funder, who has granted medRxiv a license to display the preprint in perpetuity.

It is made available under a CC-BY-NC-ND 4.0 International license .

Despite these efforts, the still limited number of identified loci that appears to modulate the relationship between clinical severity and human genetic variation

86 precludes a thoroughly understanding of inter-individual susceptibility in the disease. In

87 addition, most studies are overwhelmingly represented by European or Asian individuals

88 and whether the identified loci are also operant on individuals from other ancestry

89 backgrounds is unknown. Here we present the results from the BRACOVID study

90 enrolling 5,233 participants with distinct COVID-19 clinical presentations and from a

91 diverse population in Brazil. Our results confirm most previously identified loci and add

92 a new genome-wide significant locus associated with COVID-19 hospitalization in the

93 Brazilian population.

Results

96

The BRACOVID study was designed to identify and characterize genetic risk

98 factors for Covid-19 severity in the Brazilian population.

99

100

Relationship between demographic and clinical factors with Covid-19

101 hospitalization

102

We summarize the demographic, clinical and laboratory characteristics of the 5,233 participants of the study in Table 1 according to hospitalization necessity.

We have performed a GWAS of the genetic association architecture regarding

109 Covid-19 hospitalization need. Groups were 1,700 individuals that did not require

110 hospital admission due to Covid-19 and 3,533 individuals hospitalized due to severe

111 Covid-19. In the primary analysis, we have run 2 GWAS analysis (one for each used

112 genotyping array). Each analysis was adjusted for the first 4 Principal Components, age,

113 and sex. GWAS results were then merged using the meta-analysis routine in plink. The

114 observed genomic inflation factor for the adjusted analysis was lambda $=1.05$. 
medRxiv preprint doi: https://doi.org/10.1101/2021.10.06.21264631; this version posted October 7, 2021. The copyright holder for this preprint

115 In our main analysis, we observed one genome-wide significant locus that reached

116 the pre-defined genome-wide significant level of $5 \times 10^{-8}$ (Figure 1). We also observed

117 four additional loci that reached the pre-defined p-value threshold of $1 \times 10^{-6}$ (Table 2

118 and Supplementary Figure 1). We have run sensitivity analysis stratifying individuals by

119 their main genetic ancestral component and then conducting a trans-ethnic meta-analysis.

120 Results were very similar to those observed in the main analysis (Supplementary Figures

1212 and 3).

122

BRACOVID HGI meta-analysis:

We have replicated most previously described HGI (8) (B1 analysis) results (BRACOVID was not part of this specific HGI sub-analysis) (Supplementary File 2). Specifically, both loci at 3p21.31 and Chr21 near IFNAR2 previously associated with hospitalization need on HGI B1 analysis were nominally significant in our study with the same directionality of effect. We have also compared our results to those described by

130 HGI B2 analysis. We have observed significant associations in all previously described 131 genome-wide loci but for the one on chr9, near the ABO locus (Supplementary File 3).

In addition to looking for replicated signals within our results, we ran two meta-

133 analyses between BRACOVID hospitalization need and HGI B1 and B2 analysis. Adding

134 our results to those provided by HGI B1 analysis disclosed a genome-wide association 135 signal on chr6 that was only previously seen on the HGI B2 analysis, strengthening the 136 confidence that this locus is indeed associated with Covid-19 severity (Supplementary 137 File 4 and Supplementary Figure 4).

138 Our results meta-analyzing BRACOVID summary statistics with HGI B2 results 139 supported most previously described genome-wide association loci. Namely, for Chr1 140 near THBS3; Chr3 LZTFL1-CXCR6; Chr6 HLA-DRB1; Chr6 FOXP4; Chr11 MUC5B;

141 Chr11 ELF5; Chr12 OAS2; Chr12 P2RX2; Chr17 CRHR1; Chr19 POLD1; Chr19 142 TYK2; and Chr21 IFNAR2 regions we were able to observe concordant signals and no 143 heterogeneity of effects. We want to emphasize the observation of significant 144 heterogeneity for the previously described loci on Chr9 ABO locus; Chr21 SLC5A3; and 145 Chr17 TAC4 suggesting that these may indeed be false-positive associations due to 
medRxiv preprint doi: https://doi.org/10.1101/2021.10.06.21264631; this version posted October 7, 2021. The copyright holder for this preprint (which was not certified by peer review) is the author/funder, who has granted medRxiv a license to display the preprint in perpetuity.

It is made available under a CC-BY-NC-ND 4.0 International license .

146 population structure confounding, population-specific loci or loci associated with Covid-

14719 susceptibility and not severity (Supplementary File 5).

Local association structure suggests a population specific effect for Chr1 DSTYK

150 locus:

The newly identified genome-wide significant locus near DSTYK was not observed as significantly associated in our HGI meta-analysis. By comparing the local association structure at the DSTYK locus, it is interesting to note that HGI B2 results also suggest a sub-genome-wide significant association at the same region (Figure 2A and B). However, albeit in the same recombination interval, there is no significant colocalization of the two genetic association structures, suggesting (1) the existence of more than one causal variants within this region or (2) that different LD structures among human populations may be confounding the association pattern at this locus.

To explore these scenarios, we have first analyzed the local association structure within the Brazilian sample stratifying by different degrees of European, African, and Native American genetic ancestry among participants. Curiously, although the signal is

163 shared among the 3 groups, the strongest association signal was observed among the 164 Brazilian individuals with high European genetic ancestry (Figure 2C). In addition to this, 165 we have studied the pairwise LD between the most associated SNV in the Brazilian 166 analysis (rs11240388), and the most associated SNV in HGI B2 analysis (rs9661015).

167 Strikingly different world-wide pairwise LD patterns are observed among these 2 168 markers (Figure 2F, https://ldlink.nci.nih.gov/). In our sample, the R-square between the 169 two markers was 0.32 for participants with high European ancestry, and 0.11 for 170 participants with high African ancestry.

171 Using only individuals with high European ancestry from our Brazilian dataset we 172 delineated the associated haplotype boundaries between chr1:205131352 and 173 chr1:205210329, defining a haplotype of approximately $79 \mathrm{~Kb}$. Looking into the 174 haplotype structure of markers part of the associated haplotype we did not observe a 175 significant difference in their pairwise LD structure among Brazilians with high 176 European or high African ancestry. Using rs11240388 as a tag-SNP for our risk 
medRxiv preprint doi: https://doi.org/10.1101/2021.10.06.21264631; this version posted October 7, 2021. The copyright holder for this preprint (which was not certified by peer review) is the author/funder, who has granted medRxiv a license to display the preprint in perpetuity.

It is made available under a CC-BY-NC-ND 4.0 International license.

177 haplotype, we defined world-wide allele frequencies for the risk haplotype (Figure 2G,

178 https://popgen.uchicago.edu/ggv/). In our own sample, the frequency of the $\mathrm{G}$ allele (risk

179 allele) was $48 \%$ for the entire sample, $42 \%$ in Brazilian individuals with high European

180 ancestry and 59\% in Brazilian individuals with high African ancestry. Despite having

181 increased frequency in Brazilian individuals with high African ancestry, and as expected

182 from the stratified local association plots, the haplotype was only significantly associated

183 with Covid-19 severity in Brazilian individuals with high European genetic ancestry.

184 Taken together these results suggest that the causal variant responsible for the association

185 is present in a $79 \mathrm{~Kb}$ haplotype derived from European populations.

187 rs11240388 is also associated with several blood cell traits and with DSTYK and 188 RBBP5 gene expression levels:

Exploring the genomic annotations for the newly observed locus associated with

191 Covid-19 hospitalization we used rs11240388 as a proxy of the risk haplotype for it is in

192 complete LD with all the markers of the $79 \mathrm{~Kb}$ haplotype. Rs11240388 is located at

193 chr1:205208489 within the DSTYK gene region. The region appears to be delimited by a

194 recombination region spanning the genes CNTN2, TMEM81, RBBP5, DSTYK, and

195 TMCC2 and harbors several GeneHancer regulatory elements, most notably for CNTN2,

196 DSTYK and TMCC2 (Figure 3A). Querying the MR-base database for other phenotypes

197 previously shown to be associated with rs11240388, we observed 69 traits (Figure 3B).

198 Of particular interest to Covid-19 biology are blood cell related traits and lung associated 199 traits (Supplementary File 6).

200 Next, we explored the association structure between rs11240388 and GTEx gene 201 expression levels in all tissues and for all genes within the region (Figure 3C). Results 202 from GTEx suggest that rs11240388 is an eQTL in several tissues for CNTN2, 203 TMEM81, RBBP5 and DSTYK. Colocalization analysis between GTEx association 204 results and BRACOVID association results confirmed a significant colocalization for 205 these genes in several different tissues, suggesting that the association between the $79 \mathrm{~Kb}$ 206 risk haplotype and Covid-19 severity might be mediated through gene expression 207 modulation in the genes located in this genomic region (Figure 3D). Finally, we tested all 
medRxiv preprint doi: https://doi.org/10.1101/2021.10.06.21264631; this version posted October 7, 2021. The copyright holder for this preprint

pair-wise possibilities for colocalization: BRACOVID signal, the 69 associated traits for

the same region, and all GTEx gene-tissue results with significant colocalization (higher

211 potential intermediate mediators that could explain the association between the identified

212 risk haplotype and Covid-19 severity (Figure 3E).

\section{Discussion}

215 Covid-19 has been a world-wide pandemic for more than one year. The disease 216 has killed more than 4 million individuals and has de-stabilized entire health systems as 217 well as the world economy $(2,9,10)$. One striking characteristic of the disease is the large 218 inter-individual variability regarding its severity, ranging from asymptomatic to fatal. 219 Although several identified factors influence disease severity, predicting the overall

220 Covid-19 outcome in a particular individual remains a challenge (3-5).

Since the beginning of the pandemic, several groups worldwide have joined 222 efforts to uncover host factors. The Host Genetic Initiative (HGI) included researchers 223 and samples from different parts of the globe to focus on the inter-individual variability 224 in disease presentation (8) and outcomes and the BRACOVID is currently the largest 225 such effort in Latin America.

226 BRACOVID was designed to compare individuals with mild or asymptomatic 227 Covid-19 with those with severe Covid-19 requiring hospitalization. This contrasts with 228 most genetic studies on host determinants of Covid-19, that use individuals from the general population as their main control group. As such, BRACOVID has a more specific

230 study protocol aimed at identifying host genetic determinants of disease severity, and not 231 susceptibility.

232 The results here presented replicate most, but not all, previously reported genome233 wide significant loci associated with Covid-19 severity. These came from 3 prior 234 publications: The Severe Covid-19 GWAS Group , GenOMICC and HGI (6-8). It is 235 interesting to note that despite the large sample sizes, none of these prior studies have in 236 fact compared individuals with mild versus severe Covid-19. As such, our results confirm 237 some of the initial results regarding Covid-19 genetic determinants in a more diverse 238 population and, most importantly, within a study design to differentiate between markers 
medRxiv preprint doi: https://doi.org/10.1101/2021.10.06.21264631; this version posted October 7, 2021. The copyright holder for this preprint (which was not certified by peer review) is the author/funder, who has granted medRxiv a license to display the preprint in perpetuity.

It is made available under a CC-BY-NC-ND 4.0 International license.

of susceptibility to infection and predictors of severity. Also of importance, although BRACOVID has participated in the meta-analysis of both GenOMICC and HGI, due to

241 the analytical plan of these two prior publications, the contrast used by BRACOVID was

242 not the one presented here. Specifically, in both GenOMICC and HGI, BRACOVID

243 summary statistics were obtained by comparing hospitalized Covid-19 individuals with

244 individuals from the general Brazilian population (the last group, not included in the

245 present analysis) on what is called the HGI B2 analysis. Even in this latter situation,

246 BRACOVID sample of hospitalized individuals used in the last version of HGI analysis,

247 the one used in our meta-analysis with HGI B2, was of only 853 individuals, in contrast

248 to the more than 3,500 hospitalized participants used in the present report.

249 Besides the importance of showing replications to previously identified loci in an

250 admixed population, understanding loci that do not replicate might also be important in

251 the follow-up efforts to identify population specific determinants of Covid-19 severity.

252 One of the loci that was not replicated in our analysis is the association signal initially

253 identified in the $\mathrm{ABO}$ locus. Our results, together with the verification of intense

254 heterogeneity in signal described by HGI, suggest that the association initially described

255 at this locus may be due to confounding by population structure or other higher order 256 effects.

257 We have observed a new genome-wide significant locus associated with Covid-19

258 in our population. It is comprised by a $79 \mathrm{~Kb}$ haplotype located on chromosome 1 near the

259 DSTYK gene. The association signal in our sample was only observed in individuals with

260 high European ancestry and was not described by previous studies, suggesting it might

261 harbor a population specific risk allele or haplotype. Indeed, leveraging data from the

262 1000G project (11), we observed great inter-population differences in the haplotype

263 frequency (although an apparently constant LD structure in the region among human

264 populations).

265 Leveraging data from GTEx we were able to associate this haplotype with gene

266 expression levels of at least 5 genes: DSTYK, TMEM81, RBBP5, CNTN2 and TMCC2.

267 In addition, exploring prior publicly available GWAS data we found significant

268 associations between the identified risk haplotype and 69 different traits (8). From these,

269 using colocalization analysis, we have observed significant colocalization between 
medRxiv preprint doi: https://doi.org/10.1101/2021.10.06.21264631; this version posted October 7, 2021. The copyright holder for this preprint (which was not certified by peer review) is the author/funder, who has granted medRxiv a license to display the preprint in perpetuity.

It is made available under a CC-BY-NC-ND 4.0 International license .

270 BRACOVID results and several of these 69 traits, most strikingly a number of

271 hematological traits, including immune cell morphology and number.

272 The main limitation of this study is the lack of a suitable replication sample for

273 the GWAS results. The observed genome-wide significant locus near DSTYK needs to

274 be replicated in an independent sample to continue to be considered a modulator of

275 Covid-19 severity. The continuous effort to increase the sample size of the BRACOVID

276 study may allow the identification genome-wide significant loci with decreased effect

277 size.

278 Taken together, our analysis supports the hypothesis that the identified $79 \mathrm{~Kb}$

279 haplotype on chromosome 1 may modulate Covid-19 relevant immunological traits

280 through the gene expression of at least one of the genes with significant eQTLs in the 281 region.

283 Materials and methods

Study population

The study sample belongs to the BRACOVID Study. For the present analysis we used the first 5,233 participants enrolled in the study.

The BRACOVID study was designed to identify and characterize genetic risk

290 factors for Covid-19 severity in the Brazilian population. Participants were selected

291 through two different ascertainment processes. First, Covid-19 patients were enrolled

292 after hospitalization in one of the following tertiary care centers in the metropolitan area

293 of Sao Paulo, Brazil: Instituto do Coração, and Instituto Central do Hospital das Clínicas

294 da Faculdade de Medicina da Universidade de São Paulo. Non-hospitalized cases were 295 selected by serological studies surveys for previous SARS-CoV-2 infection or SARS-

296 CoV-2 PCR test among health professionals or the general population.

After signing an informed consent, a sample of whole-blood already collected for

298 in-hospital biochemical analysis or SARS-CoV-2 serology was used for genomic DNA 299 extraction. 
medRxiv preprint doi: https://doi.org/10.1101/2021.10.06.21264631; this version posted October 7, 2021. The copyright holder for this preprint (which was not certified by peer review) is the author/funder, who has granted medRxiv a license to display the preprint in perpetuity.

It is made available under a CC-BY-NC-ND 4.0 International license .

Participants responded to a detailed questionnaire aimed at collecting demographic, risk factors, symptoms, and prior clinical information. For hospitalized participants we extracted the data from the hospital EHR.

SNP Genotyping and Imputation

Genomic DNA extraction has been previously described (12). BRACOVID DNA 308 samples were genotyped using two different Axiom arrays: Axiom_PMRA.r3 array 309 (N=2605) or the Axiom_sarscov array ( $=2628)$ (ThermoFisher, Waltham, USA) and 310 genotypes annotated using the array specific annotation file provided at the ThermoFisher 311 website. Genotype calling was performed using Affymetrix Power Tools. Initial VCF file 312 contained 850483 (for the PMRA array) and 779972 (for the Sars-Cov array) variants 313 before quality control filtering.

314 Imputation was performed using the Haplotype Reference Consortium Michigan

315 Imputation Server using the TOPMED reference haplotype panel as reference (for mixed 316 samples). More specifically, the Michigan Imputation Server used Minimac4 to conduct 317 imputation on 658,357 SNPs remaining after data quality control. After imputation data 318 were exported in the standard PLINK format, downstream QC procedures and statistical 319 analysis were conducted using the latest PLINK 320 (http://pngu.mgh.harvard.edu/_purcell/plink) and R software packages (http://www.r321 project.org/), installed on a Linux based computation resource. Specifically, imputation 322 markers were kept if R2 > 0.3, and minor allele frequency (MAF) > 0.01. A HWE p-

323 value $<1 \times 10^{-20}$ was used to control for potential genotyping clustering problems. 324 Genetic population structure was determined through PCA analysis after LD-pruning of 325 associated markers (see also Statistical Analysis section). A total of 11,395,074 SNPs 326 were used for genome-wide analyses, 10,981,197 for autosomal, and 413,877 for X327 chromosomal analysis. 
medRxiv preprint doi: https://doi.org/10.1101/2021.10.06.21264631; this version posted October 7, 2021. The copyright holder for this preprint (which was not certified by peer review) is the author/funder, who has granted medRxiv a license to display the preprint in perpetuity.

It is made available under a CC-BY-NC-ND 4.0 International license .

We used a dichotomous category defined among SARS-CoV-2 participants. We

332 have grouped individuals that did not require hospitalization into the control group

333 (participants ascertained through population-based serological prevalence studies that did

334 not have a prior history of hospitalization due to Covid-19) and hospitalized individuals

335 (ascertained at the first hospital admission day) in the case group. Baseline categorical

336 parameters are presented using frequencies (proportions), continuous parameters are

337 presented using mean \pm SD.

338 Genome-wide association analyses were conducted using plink. We have 339 conducted two analyses one without any further adjustment and one adjusting for the first

340 four principal components, age, sex, and array type. The threshold for genome-wide

341 significance was set to $p<5 \times 10^{-8}$. Associations with $p<1 \times 10^{-6}$ were considered as

342 suggestive and presented as a list of top associated SNPs.

343 Due to the high level of admixture and complex genetic population structure

344 present in the Brazilian population we have conducted different sensitivity analysis

345 taking into consideration the individual position on the PCA plot generated using the 2

346 first principal components. Briefly, for the PCA-defined subgroup analysis we have k-

347 means clustering with $\mathrm{k}=3$ and defined three different subgroups with higher European,

348 African, and Native-American ancestries. Meta-analysis used a fixed-effect model and

349 was calculated using plink - meta-analysis routine.

350 Local association plots were created using LocusZoom (13). Local linkage disequilibrium

351 structure was determined using Haploview (14).

\section{PheWas analysis}

After identifying SNV that could be proxies of the associated haplotype we have 356 used MR-base through the R package ieugwasr to search for prior GWAS studies

357 reporting significant levels of association between a trait and the selected tag-SNV. The 358 used $p$ value cut-off level for this phewas analysis was $p<1 \times 10^{-5}$.

\section{Colocalization analysis}


medRxiv preprint doi: https://doi.org/10.1101/2021.10.06.21264631; this version posted October 7, 2021. The copyright holder for this preprint (which was not certified by peer review) is the author/funder, who has granted medRxiv a license to display the preprint in perpetuity.

It is made available under a CC-BY-NC-ND 4.0 International license.

For colocalization analysis we have defined a window spanning $400 \mathrm{~Kb}$ centered

363 at the most associated variant in all regions classified as having a suggestive association

364 signal. Information on all variants within this region was used for colocalization testing.

365 We have used the R package coloc for colocalization analysis. Briefly, all genes residing

366 in each selected region with their expression quantitative trait loci (eQTL) summary

367 statistics available in GTEx V8.0 were sequentially tested for colocalization with the

368 results obtained for Covid-19 severity association. As reference LD structure we used

3691000 genomes 2012 European LD matrix (our sample has approximately 80\% European

370 ancestry). Colocalization was tested against all 48 tissues available in GTEx V8.0 and

371 against all traits with significant association to the selected variant (as described in the

372 phewas section). We used a threshold of $\mathrm{H} 4$ (the posterior probability that a single causal

373 variant, or haplotype, could explain the local association pattern of both tested traits) >

3740.7 as evidence for significant colocalization.

Acknowledgements

377 The BRACOVID project received an unrestricted financial support from JBS S.A.

378 Company, Sao Paulo, Brazil and from the general public under the HC-COMVIDA

379 crowdfunding scheme (https://viralcure.org/c/hc). The funds were managed by Fundação

380 Zerbini and Fundação Faculdade de Medicina, respectively. We are thankful for the infra-

381 structure support for sample collection provided by the HCFMUSP Covid-19 Study

382 Group. We are also grateful to the Host Genetic Initiative for making their data publicly

383 available (full acknowledgements can be found at

384 https://www.covid19hg.org/acknowledgements/).

386 Conflict of interest 
medRxiv preprint doi: https://doi.org/10.1101/2021.10.06.21264631; this version posted October 7, 2021. The copyright holder for this preprint (which was not certified by peer review) is the author/funder, who has granted medRxiv a license to display the preprint in perpetuity.

It is made available under a CC-BY-NC-ND 4.0 International license .

The authors certify that they have NO affiliations with or involvement in any organization or entity with any financial interest in the subject matter or materials discussed in this manuscript.

\section{References}

392 1. Zhu N, Zhang D, Wang W, Li X, Yang B, Song J, et al. A Novel Coronavirus from

393 Patients with Pneumonia in China, 2019. N Engl J Med. 2020;382(8):727-33.

394 2. COVID-19 Dashboard by the Center for Systems Science and Engineering (CSSE)

395 at Johns Hopkins University (JHU) [Internet]. 2021. Available from: https://coronavirus.jhu.edu/map.html

3. Morens DM, Fauci AS. Emerging Pandemic Diseases: How We Got to COVID-

4. Casanova J-L, Abel L. Lethal Infectious Diseases as Inborn Errors of Immunity: Toward a Synthesis of the Germ and Genetic Theories. Annu Rev Pathol. 2021

6. Genomewide Association Study of Severe Covid-19 with Respiratory Failure. N Jan;16:23-50.

408 7. Pairo-Castineira E, Clohisey S, Klaric L, Bretherick AD, Rawlik K, Pasko D, et al. 409 Genetic mechanisms of critical illness in COVID-19. Nature. 2021;591(7848):92$410 \quad 8$.

411 8. Ganna A, Unit TG, General M. The COVID-19 Host Genetics Initiative, a global 412 initiative to elucidate the role of host genetic factors in susceptibility and severity 413 of the SARS-CoV-2 virus pandemic. Eur J Hum Genet. 2020;28(6):715-8.

414 9. Weinstein M, Skinner J. Covid-19 - Implications for the Health Care System 415 David. N Engl J Med. 2011;362(5):567-71.

416 10. Allain-Dupré D, Chatry I, Michalun V, Moisio A. The territorial impact of 
COVID-19 $\square$ : managing the crisis across levels of government. OECD Tackling

418 Coronavirus. 2020. p. 2-44.

419 11. Altshuler DL, Durbin RM, Abecasis GR, Bentley DR, Chakravarti A, Clark AG, et

420 al. A map of human genome variation from population-scale sequencing. Nature. 2010;467(7319):1061-73.

422 12. Preparation S, No DP. Axiom ${ }^{\mathrm{TM}} 2.0$ gDNA Sample Preparation [Internet]. p. 2-5.

423 Available from: https://www.thermofisher.com/us/en/home/technical-

424 resources/contact-us.html?supportType=TS

425 13. Boughton AP, Welch RP, Flickinger M, VandeHaar P, Taliun D, Abecasis GR, et

426 al. LocusZoom.js: Interactive and embeddable visualization of genetic association 427 study results. Bioinformatics. 2021 Mar;

428 14. Barrett JC, Fry B, Maller J, Daly MJ. Haploview: analysis and visualization of LD 429 and haplotype maps. Bioinformatics. 2005 Jan;21(2):263-5.

\section{Supporting Information}

\section{Tables:}

433 Table 1. Demographic, clinical and laboratory characteristics of studied subjects 434 according to hospitalization need. 
medRxiv preprint doi: https://doi.org/10.1101/2021.10.06.21264631; this version posted October 7, 2021. The copyright holder for this preprint (which was not certified by peer review) is the author/funder, who has granted medRxiv a license to display the preprint in perpetuity.

It is made available under a CC-BY-NC-ND 4.0 International license.

\begin{tabular}{|c|c|c|c|}
\hline Patients' characteristics & Total $\mathbf{n}(\%)$ & $\begin{array}{c}\text { Hospitalization } \mathbf{n} \\
\text { (\%) }\end{array}$ & $\begin{array}{c}\text { Non-hospitalization } \mathbf{n} \\
(\%)\end{array}$ \\
\hline & $5233(100)$ & $3533(67.5)$ & $1700(32.5)$ \\
\hline \multicolumn{4}{|l|}{ Demographic characteristics } \\
\hline \multicolumn{4}{|l|}{ Age categories } \\
\hline$<18$ & $5(0.1)$ & $5(0.1)$ & $0(0)$ \\
\hline 18-49 (average: 36 ) & $2308(45)$ & $986(28)$ & $1322(80.7)$ \\
\hline 50-64 (average: 57) & $1423(27.5)$ & $1156(32.8)$ & $267(16.3)$ \\
\hline$>65$ (average: 74) & $1424(27.6)$ & $1371(39)$ & $49(3)$ \\
\hline \multicolumn{4}{|l|}{ Sex } \\
\hline Female & $2838(54)$ & $1626(46)$ & $1212(71.4)$ \\
\hline Male & $2391(45.8)$ & $1906(54)$ & $485(28.6)$ \\
\hline \multicolumn{4}{|l|}{ Race/ethnicity } \\
\hline White & $3409(66)$ & $2453(70.8)$ & $956(56.2)$ \\
\hline Brown & $1183(23)$ & $684(19.7)$ & $499(29.4)$ \\
\hline Black & $445(8.6)$ & $244(7)$ & $201(11.8)$ \\
\hline Native Brazilian & $5(0.1)$ & $1(0.02)$ & $4(0.2)$ \\
\hline Asian & $69(1.3)$ & $39(1.1)$ & $30(1.8)$ \\
\hline Other & $6(0.1)$ & $4(0.1)$ & $2(0.1)$ \\
\hline \multicolumn{4}{|l|}{ Health characteristics } \\
\hline Hypertension & $2185(42)$ & $1937(55.3)$ & $248(14.7)$ \\
\hline Cardiovascular Disease & $1021(20)$ & $996(29.6)$ & $25(1.5)$ \\
\hline ACEi users & $431(9.5)$ & $395(13.7)$ & $36(2.2)$ \\
\hline Asthma & $239(4.6)$ & $172(4.9)$ & $67(4)$ \\
\hline Tabagism & $1002(19.4)$ & $833(24)$ & $169(10)$ \\
\hline COPD & $219(4.2)$ & $213(6.1)$ & $6(0.4)$ \\
\hline Diabetes melitus & $1329(25.7)$ & $1238(35.4)$ & $91(5.4)$ \\
\hline HIV & $35(0.7)$ & $33(0.9)$ & $2(0.1)$ \\
\hline CKD & $449(8.7)$ & $441(12.6)$ & $8(0.5)$ \\
\hline \multicolumn{4}{|l|}{ BMl statusd } \\
\hline Obese (BMI of $30 \mathrm{~kg} / \mathrm{m}^{2}$ or greater) & $1186(32.2)$ & $735(36.4)$ & $447(26.8)$ \\
\hline Overweight (BMI of $25-29.9 \mathrm{~kg} / \mathrm{m}^{2}$ ) & $1341(36.4)$ & $683(33.8)$ & $659(39.6)$ \\
\hline Normal (BMl of $20-24.9 \mathrm{~kg} / \mathrm{m}^{2}$ ) & $984(26.7)$ & $489(24.2)$ & $496(29.8)$ \\
\hline BMl of $20 \mathrm{~kg} / \mathrm{m}^{2}$ or lower & $176(4.8)$ & $113(5.6)$ & $63(3.8)$ \\
\hline Cancer & $191(3.7)$ & $170(4.9)$ & $21(1.2)$ \\
\hline Autoimmune diseases & $132(2.6)$ & $101(2.9)$ & $31(1.8)$ \\
\hline \multicolumn{4}{|l|}{ Case severity } \\
\hline Hospitalization & $3533(67.5)$ & $3533(100)$ & $0(0)$ \\
\hline $\mathrm{ICU}$ & $2186(41.8)$ & $2186(62.6)$ & $0(0)$ \\
\hline Oxygen & $2621(50.1)$ & $2619(75.1)$ & $2(0.1)$ \\
\hline No-invasive ventilation & $1263(24.1)$ & $1263(36.2)$ & $0(0)$ \\
\hline Mechanical ventilation & $1521(29.1)$ & $1521(43.6)$ & $0(0)$ \\
\hline Dialysis & $511(9.8)$ & $511(14.8)$ & $0(0)$ \\
\hline \multicolumn{4}{|l|}{ Vaccination status } \\
\hline Yes (2 doses) & $856(16.4)$ & $60(1.7)$ & $796(46.8)$ \\
\hline Yes (1 dose) & $102(1.9)$ & $58(1.6)$ & $44(2.6)$ \\
\hline No & $4275(81.7)$ & $3415(96.7)$ & $860(50.6)$ \\
\hline
\end{tabular}

436 ACEi: Angiotensin-converting enzyme inhibitors; BMI: Body Mass Index; CKD: 437 Chronic kidney disease; COPD: Chronic obstructive pulmonary disease; HIV: 438 Human immunodeficiency virus; ICU: Intensive care unit; NA: Not available.

440 Table 2. Genome-wide significant and suggestive loci identified in BRACOVID Covid-

44119 severity analysis. 
medRxiv preprint doi: https://doi.org/10.1101/2021.10.06.21264631; this version posted October 7, 2021. The copyright holder for this preprint (which was not certified by peer review) is the author/funder, who has granted medRxiv a license to display the preprint in perpetuity.

It is made available under a CC-BY-NC-ND 4.0 International license .

\begin{tabular}{|c|c|c|c|c|c|c|c|}
\hline $\mathrm{CHR}$ & $\mathrm{BP}$ & SNP & Effect Allele & $\mathrm{P}$ & OR & Genes & \\
\hline 1 & 205208489 & chr1:205208489:G:A & G & 3.99E-08 & 1.3516 & \multicolumn{2}{|c|}{ RBBP5, DSTYK, TMCC2 } \\
\hline 2 & 45584979 & chr2:45584979:T:C & C & $4.06 \mathrm{E}-07$ & 0.7509 & SRBD1 & \\
\hline 4 & 25613313 & chr4:25613313:G:A & $A$ & $3.21 \mathrm{E}-07$ & 1.4647 & SLC34A2 & \\
\hline 5 & 21768177 & chr5:21768177:G:A & $A$ & $5.02 \mathrm{E}-07$ & 1.3263 & \multicolumn{2}{|c|}{ GUSBP1, CDH12 } \\
\hline 10 & 22439346 & chr10:22439346:T:C & C & $5.96 \mathrm{E}-07$ & 0.549 & PIP4K2A & \\
\hline
\end{tabular}

443 Figures:

444 Figure 1. Manhattan plot of BRACOVID results for Covid-19 hospitalization. Results

445 from a logistic regression model adjusted for the first 4 PCs, age, and sex for each used

446 genotyping array were meta-analyzed using a fixed-effect meta-analysis.

448 Figure 2. Association and LD structure at Chr1 DSTYK associated locus. A. Local

449 association structure of BRACOVID hospitalization analysis; B. Local association

450 structure of HGI B2 analysis; C. Local association structure for BRACOVID European

451 cluster; D. Local association structure for BRACOVID African cluster; E. Local

452 association structure for BRACOVID Native American cluster; F. World-wide

453 distribution of pairwise LD between rs11240388 (local maximum for BRACOVID

454 analysis) and rs9661015 (local maximum for HGI B2 analysis); G. 1000G allele

455 frequency distribution for rs 11240388.

456 Figure 3. Annotation and functional characterization of Chr1 DSTYK associated region.

457 A. Genomic anatomy of associated region. Blue highlight - 79Kb associated haplotype.

458 B. Phewas results and colocalization analysis with BRACOVID summary statistics.

459 Colocalization values are depicted as a function of their $\mathrm{H} 3$ and $\mathrm{H} 4$ posterior

460 probabilities. Positive values (blue spectrum) for higher H4 values than H3, negative

461 values (red spectrum) for higher H3 than H4. Inner circle represents study/database of

462 trait being colocalized with BRACOVID results. Black: Datasets that satisfy minimum

463 requirements imported from the EBI database of complete GWAS summary data; red: 
medRxiv preprint doi: https://doi.org/10.1101/2021.10.06.21264631; this version posted October 7, 2021. The copyright holder for this preprint (which was not certified by peer review) is the author/funder, who has granted medRxiv a license to display the preprint in perpetuity.

It is made available under a CC-BY-NC-ND 4.0 International license .

464 eqtlGen 2019 results; green: GWAS summary datasets generated by many different 465 consortia that have been manually collected and curated, initially developed for MR-Base 466 (round 2); dark blue: Complete GWAS summary data on protein levels as described by 467 Sun et al 2018; magenta: Complete GWAS summary data on brain region volumes as 468 described by Elliott et al 2018; pink: Neale lab analysis of UK Biobank phenotypes, 469 round 2; C. Association structure between rs11240388 and genes within its genomic 470 region using 42 tissues in GTEx V8. Red rectangles are for association p values below

471 0.01. Numbers within cells represent the normalized mean expression value within tissue 472 for gene; D. Colocalization results between BRACOVID summary statistics for 473 rs11240388 region and different GTEx V8 gene/tissue combinations. Shown are only the 474 most significant $\mathrm{H} 4$ probability results; E. Causal diagram derived from pairwise 475 comparisons with significant colocalization at rs11240388 region.

477 Supplementary Figures:

478 Supplementary Figure 1. Local association plots for the 4 suggestive associated loci.

479 Suggestive association was defined as a p-value between 1 x 10-6 and 5 x 10-8. Genome 480 positions in $\mathrm{Hg} 19$.

481 Supplementary Figure 2. K-means clustering (k=3) of BRACOVID participants using 482 the first and second PCs. Orange triangle - European cluster; Green circle - African 483 cluster; Purple square - Native American cluster.

484 Supplementary Figure 3. Manhattan plots of ancestry clusters and trans-ethnic meta485 analysis. A. European cluster; B. African cluster; C. Native American cluster; D. Native 486 American cluster.

487 Supplementary Figure 4. Local association structure for Chr6 FOXP4 region.

488 Supplementary Figure 5. Pairwise colocalization results for all pairwise combinations 489 of significant GTEx gene/tissue pairs, traits associated with rs11240388 in the phewas 490 analysis and BRACOVID hospitalization results for the rs11240388 region. Red 
medRxiv preprint doi: https://doi.org/10.1101/2021.10.06.21264631; this version posted October 7, 2021. The copyright holder for this preprint

(which was not certified by peer review) is the author/funder, who has granted medRxiv a license to display the preprint in perpetuity.

It is made available under a CC-BY-NC-ND 4.0 International license.

491 spectrum for colocalization results where $\mathrm{H} 3$ posterior probability $>\mathrm{H} 4$ posterior

492 probability. Blue spectrum for colocalization results where $\mathrm{H} 4$ posterior probability $>\mathrm{H} 3$

493 posterior probability.

494

495 Supplementary files

496 Supplementary File 1. Replication results from BRACOVID for HGI B1 analysis

497 genome-wide significant loci.

498 Supplementary File 2. Replication results from BRACOVID for HGI B2 analysis

499 genome-wide significant loci.

500 Supplementary File 3. Genome-wide significant hits from meta-analysis BRACOVID

501 versus HGI B1 model.

502 Supplementary File 4. Genome-wide significant hits from meta-analysis BRACOVID

503 versus HGI B2 model.

504 


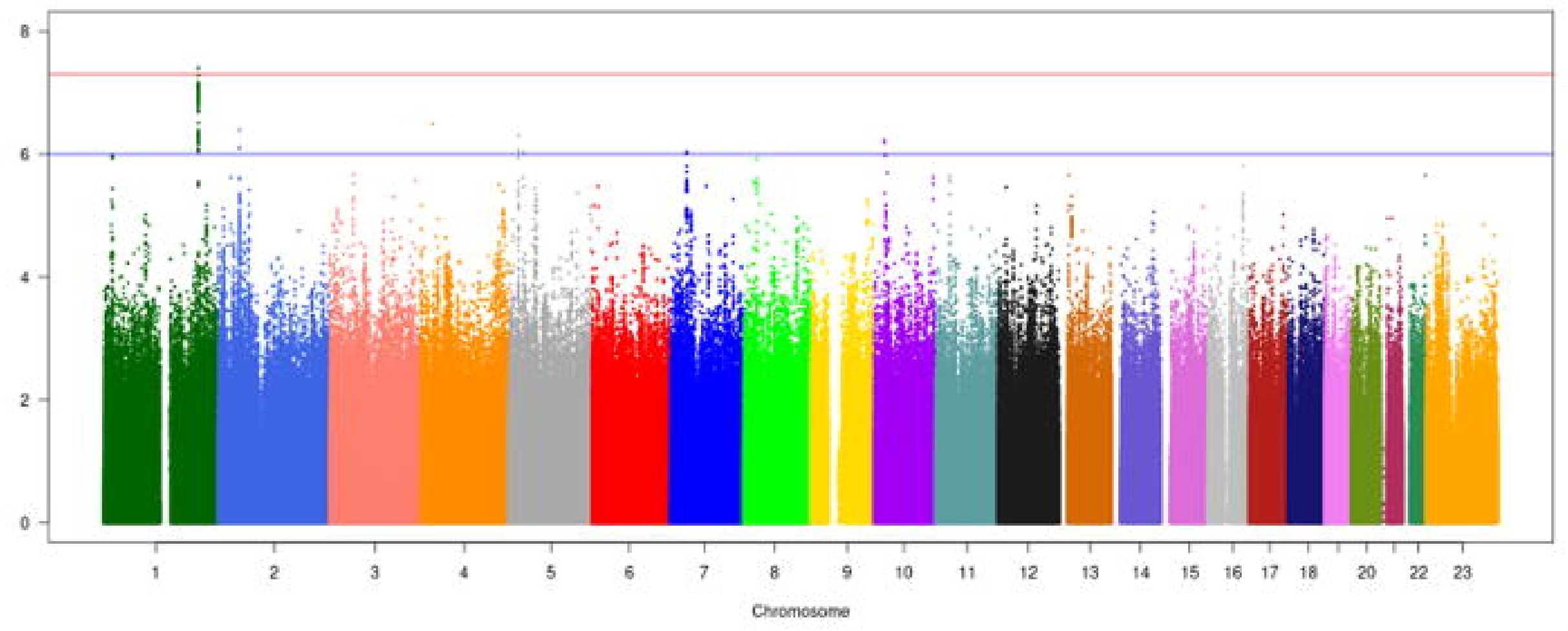




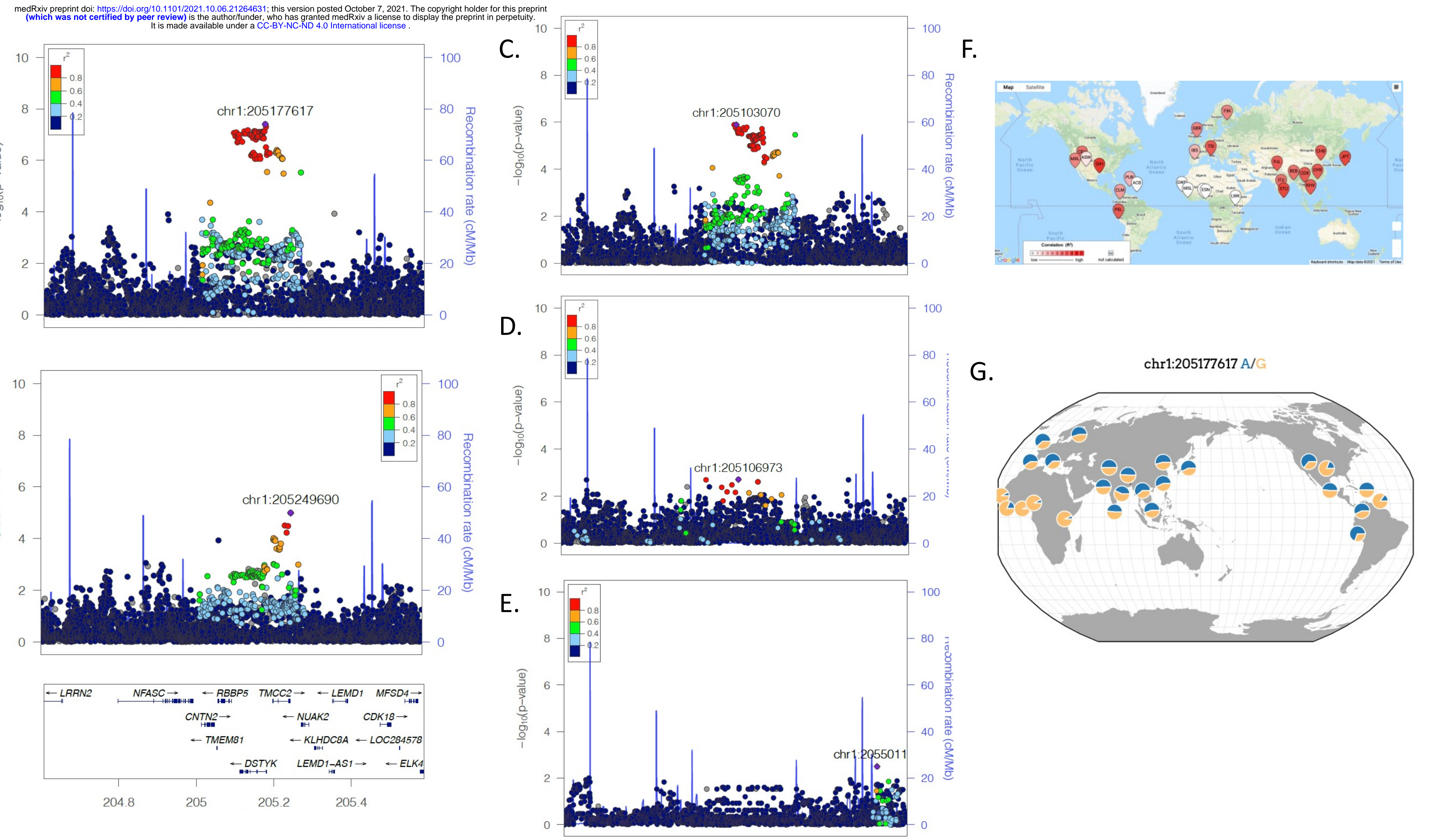



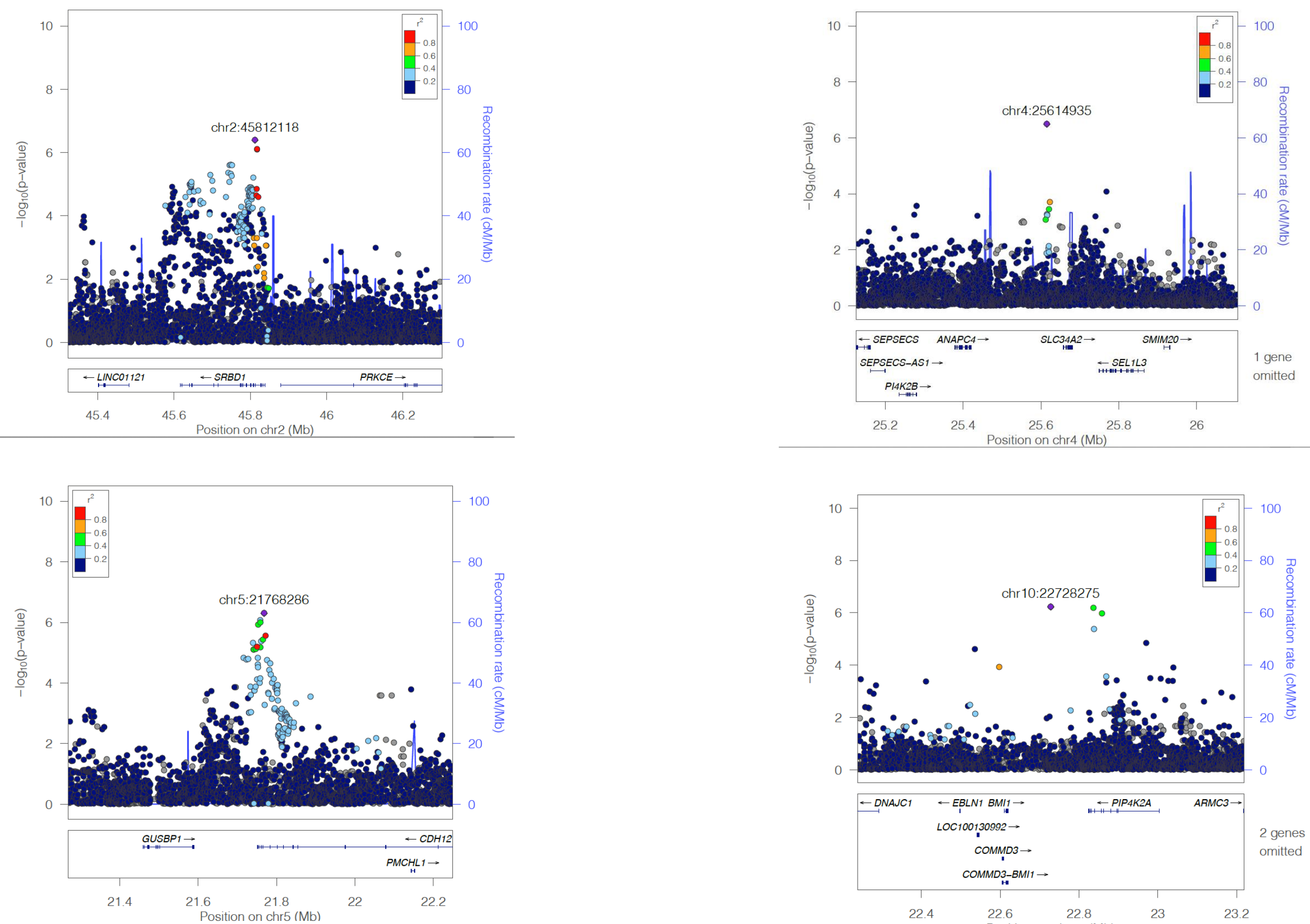


\section{Cluster plot}

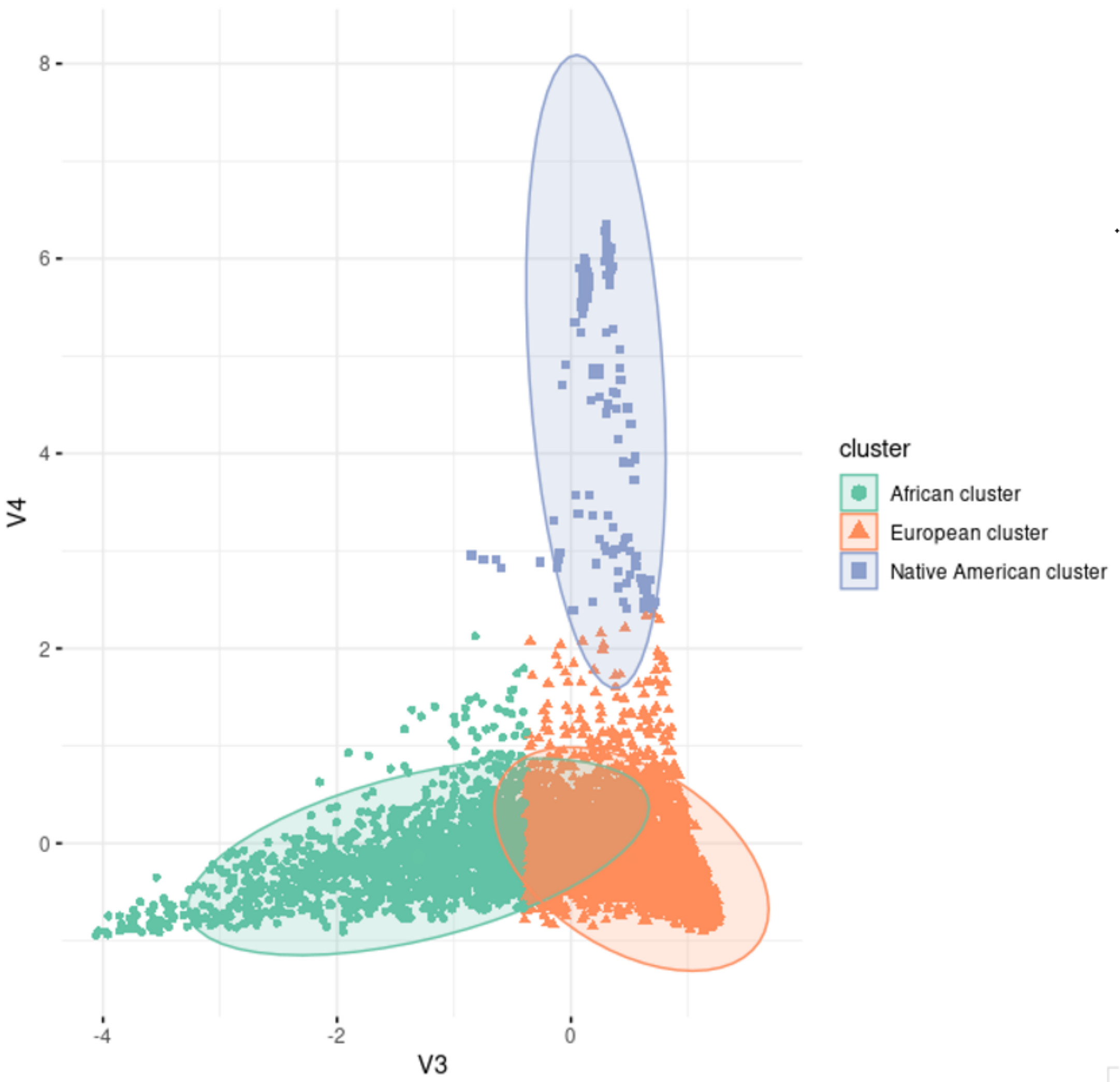



A.
B.
c.
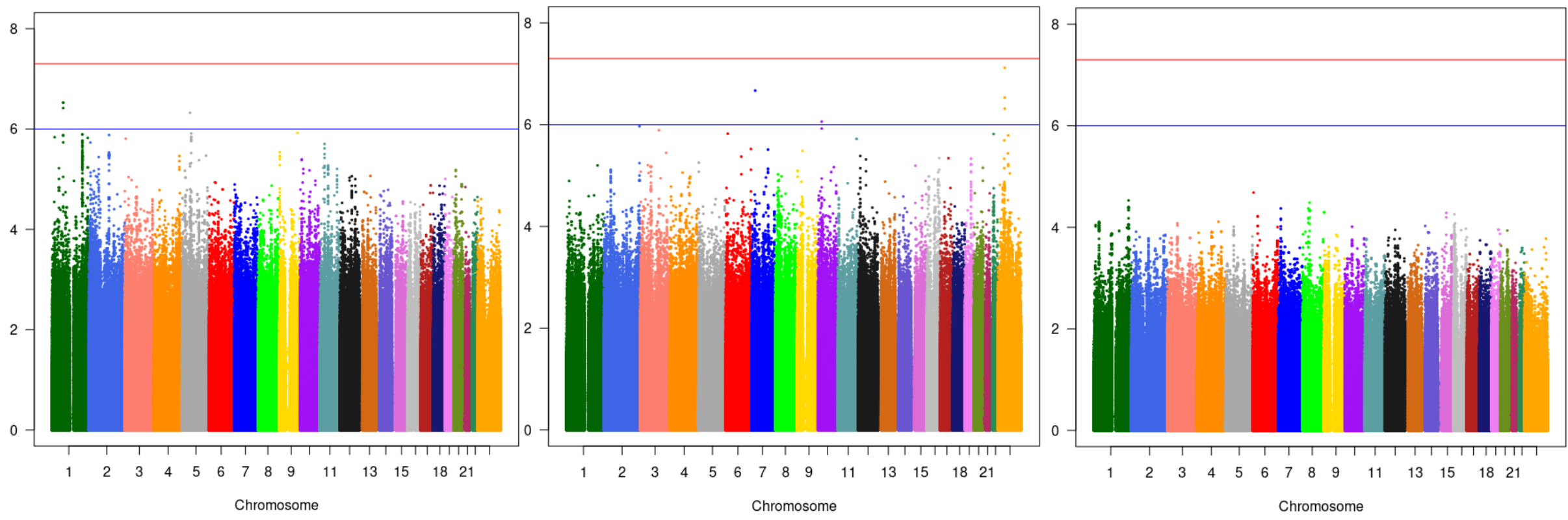

D.

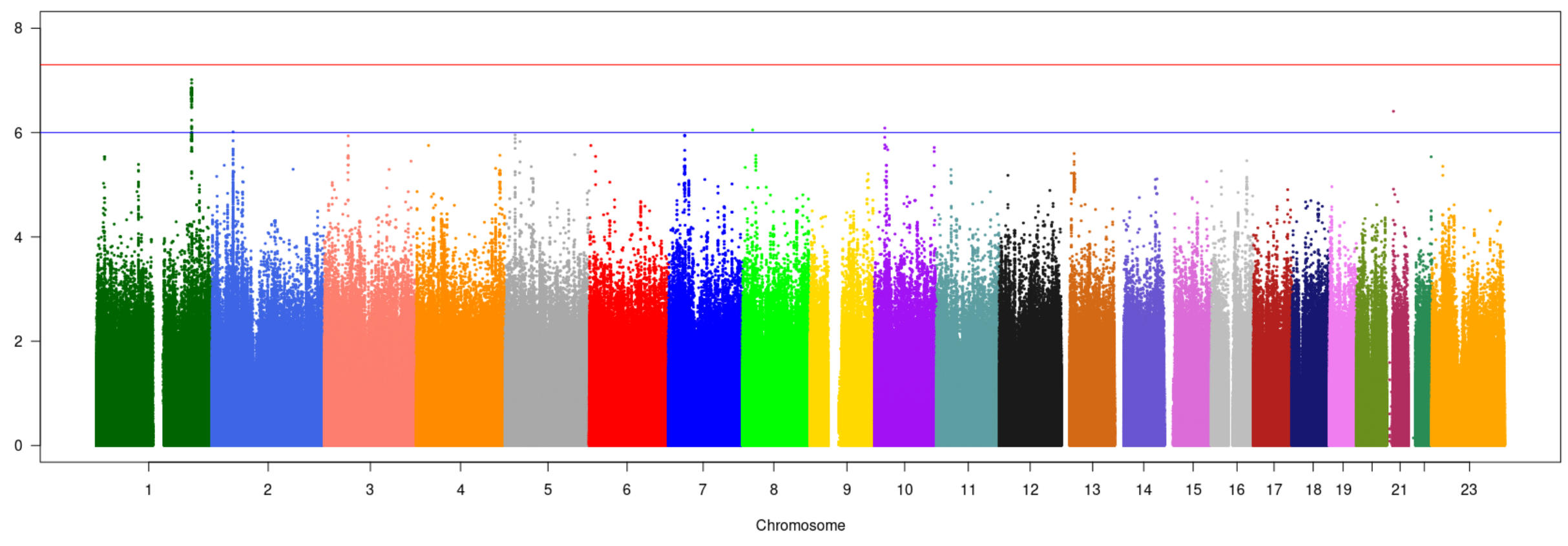




\section{6:41512355}

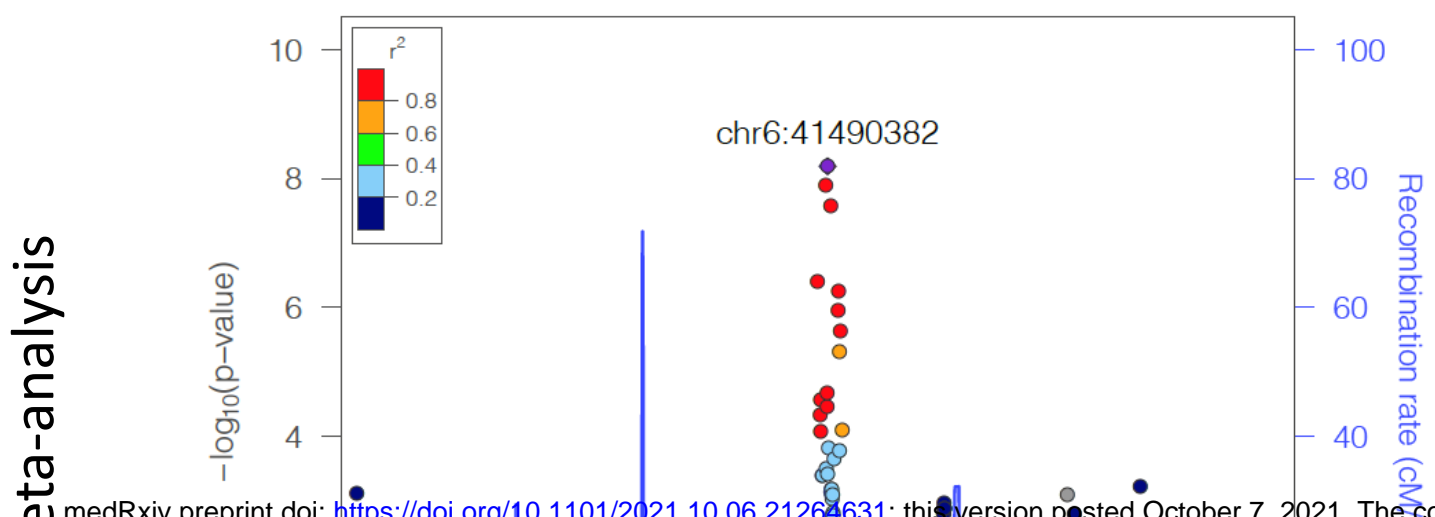

(1) medRxiv preprint doi: https://doi.org/10.1101/2021.10.06.21264631; thi Spersion posted October 7, 2021. The-copyright holder for this pre

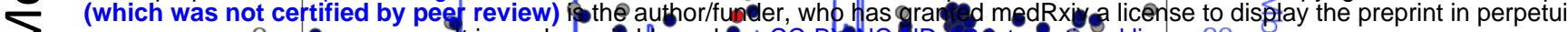
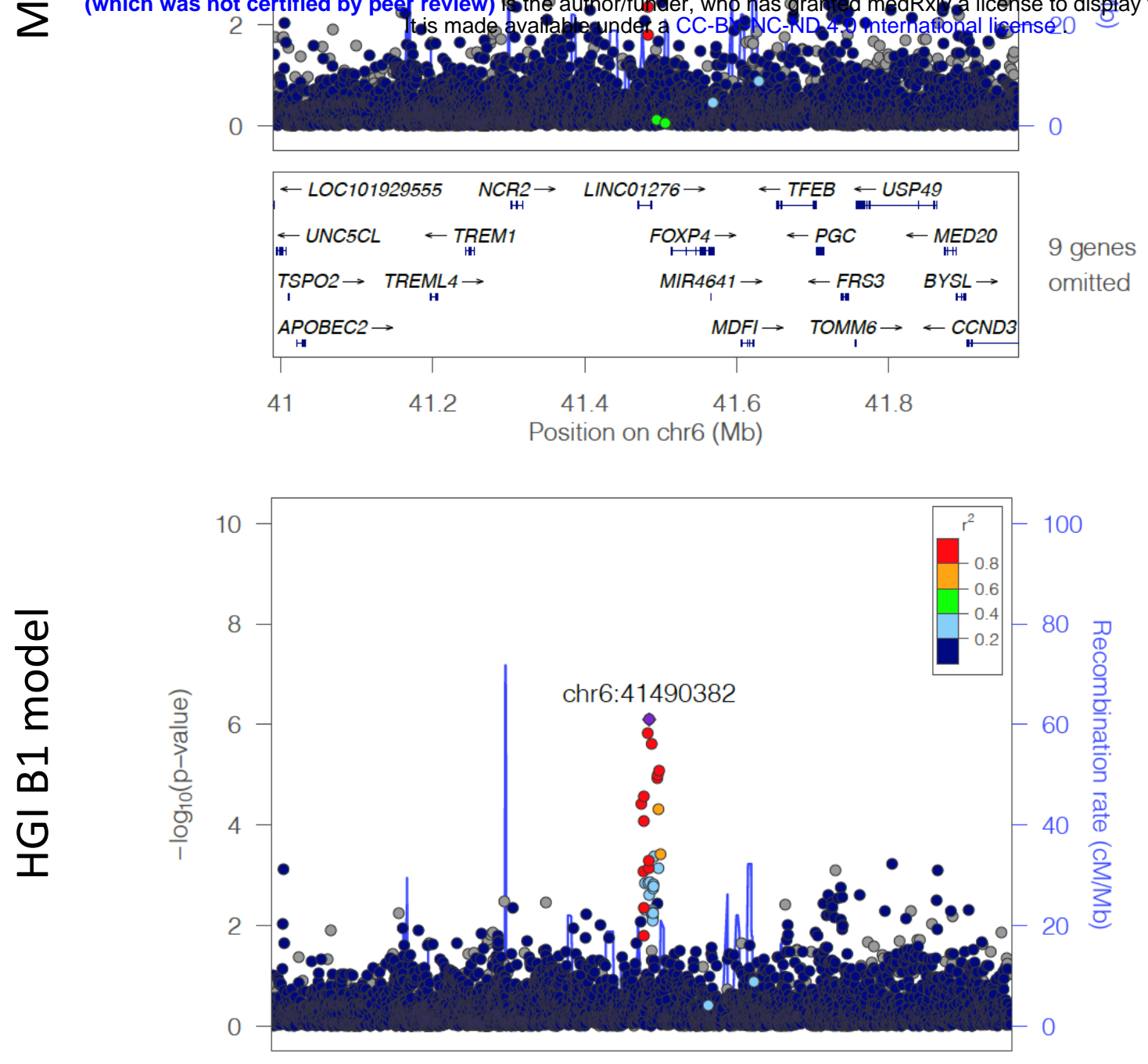

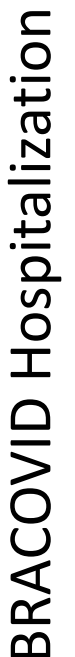

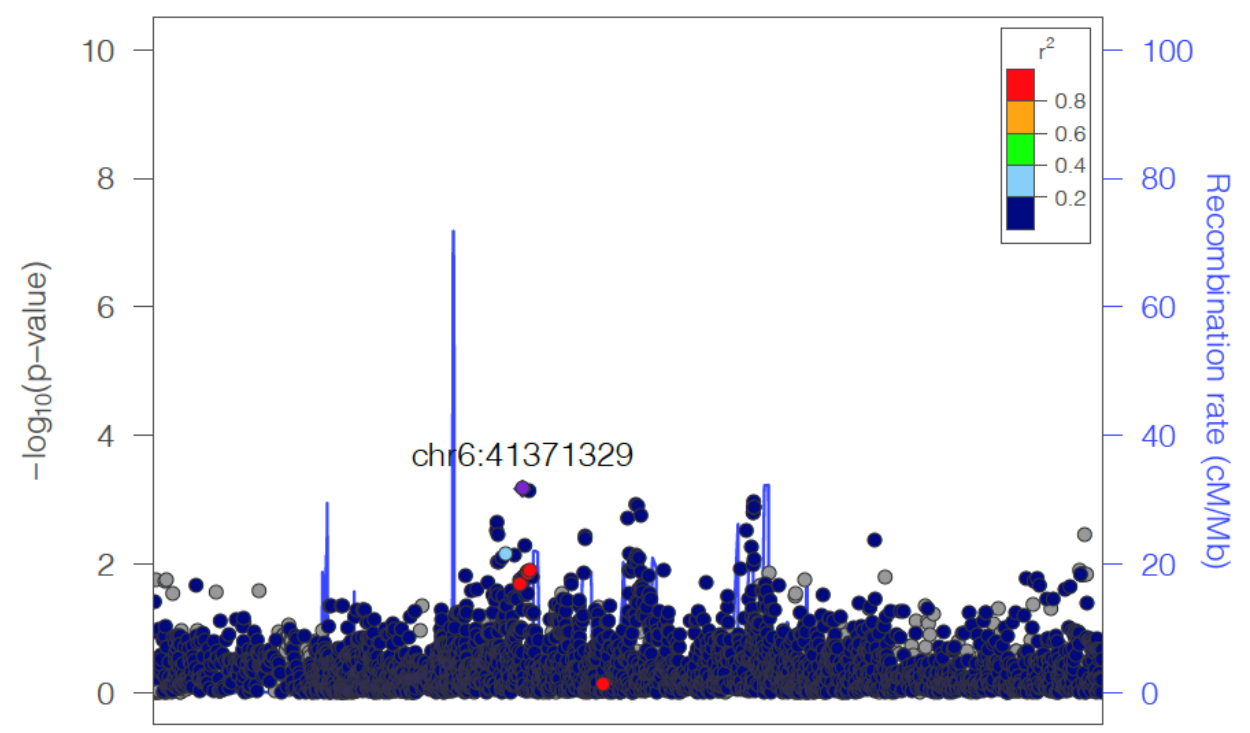




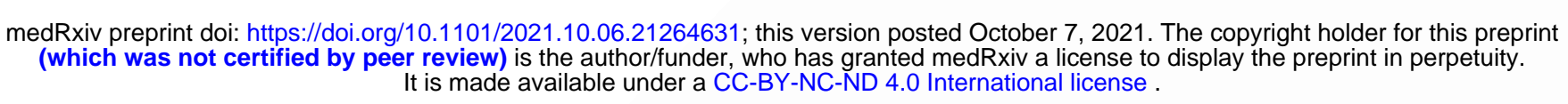

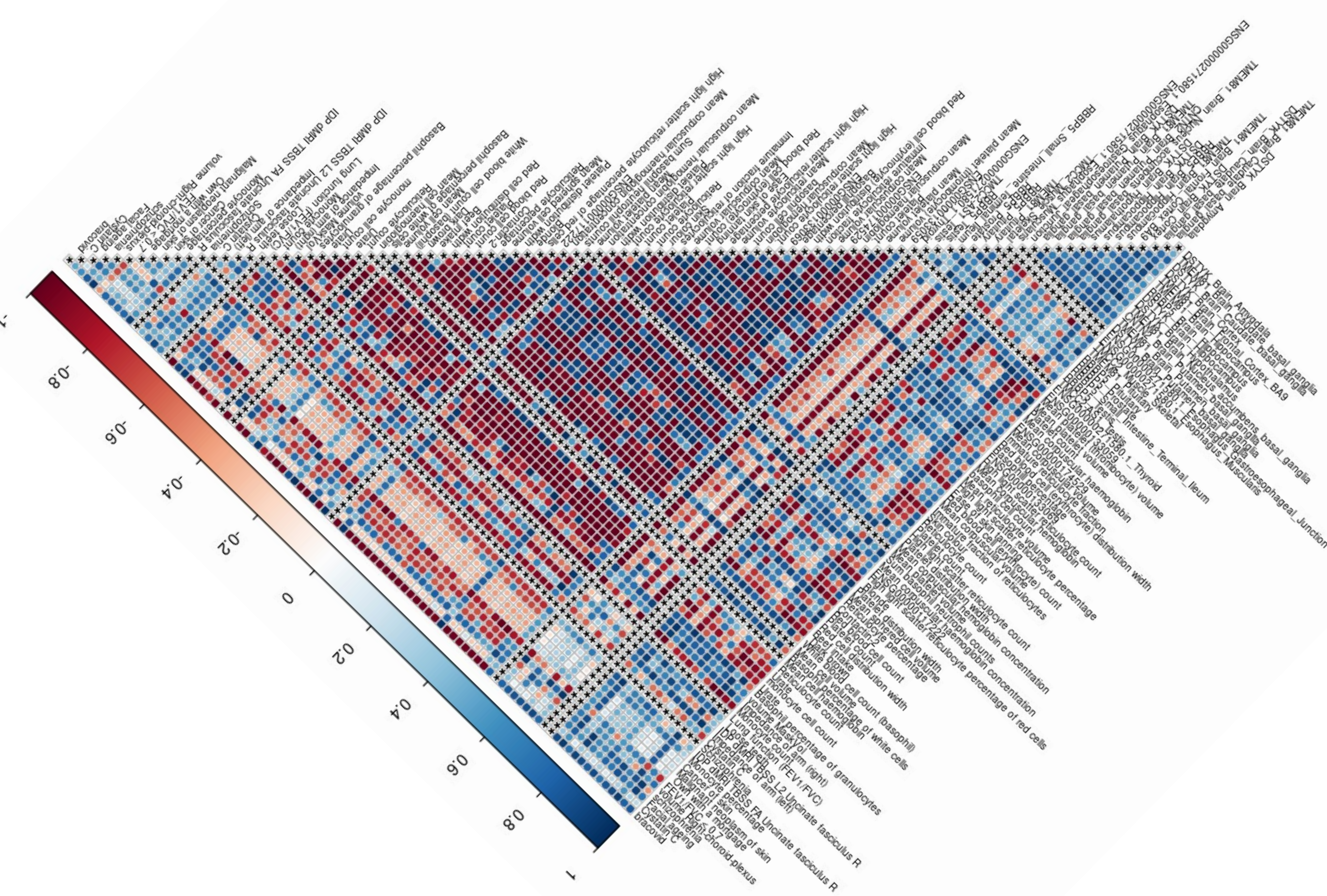

